\section{A viral caspase contributes to modified apoptosis for virus transmission}

\author{
Dennis K. Bideshi, ${ }^{1,2,4}$ Yeping Tan, ${ }^{1,4}$ Yves Bigot, ${ }^{3}$ \\ and Brian A. Federici ${ }^{1,5}$ \\ ${ }^{1}$ Department of Entomology and Interdepartmental Graduate \\ Programs in Genetics, Microbiology, and Cell Biology, \\ University of California at Riverside, Riverside, California \\ 92521, USA; ${ }^{2}$ Department of Natural and Mathematical \\ Sciences, California Baptist University, Riverside, California \\ 92504, USA; ${ }^{3}$ Laboratoire d'Etude des Parasites Génétiques, \\ Université François Rabelais, UFR Sciences et Techniques, \\ 37200 Tours, France
}

The Spodoptera frugiperda ascovirus, a DNA virus that attacks lepidopterans, codes for an executioner caspase synthesized by $9 \mathrm{~h}$ after infection of Sf21 cells. This caspase alone induces apoptosis in insect cells and, during viral replication in vivo, contributes to a novel cell cleavage process in which developing apoptotic bodies are rescued by the virus and differentiate to form large vesicles in which virions assemble. These viral vesicles disseminate to the blood, where they are acquired during egg-laying by parasitic wasps that transmit the virus. No other viruses encode caspases or form such modified apoptotic bodies, suggesting this caspase plays a direct role in cell partitioning that facilitates viral reproduction and transmission.

Supplemental material is available at http://www.genesdev.org.

Received January 20, 2005; revised version accepted May 5, 2005.

Ascoviruses are complex double-stranded DNA viruses that attack lepidopterans, most commonly species of the family Noctuidae. Virions of these viruses are enveloped, bacilliform to allantoid in shape and $400 \mathrm{~nm}$ in length, and contain circular genomes, which, depending on the species, range from 116 to $180 \mathrm{kbp}$ (Federici et al. 2000). An unusual feature of ascoviruses in comparison to most other viruses that attack invertebrates is that they are poorly infectious per os (Govindarajan and Federici 1990). Instead, laboratory experiments and ecological studies have shown that these viruses are transmitted mechanically by female parasitic wasps during oviposition. The ovipositor of the female wasp becomes contaminated with virions and virion-containing vesicles when inserted into an infected host to lay eggs. Subsequent oviposition in other caterpillars transfers virions to new hosts, resulting in their infection and death as well as the death of wasp progeny (Hamm et al. 1985;

[Keywords: Viral caspase; apoptosis; ascovirus; viral vesicles]

${ }^{4}$ These authors contributed equally to this work.

${ }^{5}$ Corresponding author.

E-MAIL brian.federici@ucr.edu; FAX (951) 827-3086.

Article published online ahead of print. Article and publication date are at http://www.genesdev.org/cgi/doi/10.1101/gad.1300205.
Govindarajan and Federici 1990; Tillman et al. 2004). An interesting exception to this transmission pattern is the ascovirus that attacks pupae of the leak moth, Acrolepiosis assectella. The genome of this ascovirus is carried unintegrated in the nuclei of males and females of its wasp vector, Diadromus pulchellus, and virions are transmitted vertically during oviposition by the wasp, which is highly dependent on this virus for parasitic success (Bigot et al. 1997).

While the transmission of ascoviruses is unusual for an insect virus, the most novel feature of these viruses compared with all others is their reproductive cellular biology. After infecting a cell, these viruses initiate a cytopathology that resembles apoptosis, but in vivo differs significantly in several features. Within a few hours of infection, the nuclear membrane invaginates and then fragments (Federici 1983; Federici and Govindarajan 1990). Subsequently, rather than shrink and form characteristic apoptotic bodies by blebbing as cell death proceeds, the cell hypertrophies, enlarging as much as 10 times the size of healthy cells (Federici and Govindarajan 1990). As the cell enlarges, the plasma membrane invaginates as part of process that cleaves the cell into numerous virion-containing vesicles, $5-10 \mu \mathrm{m}$ in diameter, which subsequently disperse to the hemolymph (Federici 1983). Virion assembly continues in these vesicles as they circulate in the hemolymph, where they contaminate the ovipositor of parasitic wasps during oviposition for transmission to the next host (Federici and Govindarajan 1990; Tillman et al. 2004).

In eucaryotic cells, apoptosis is a common response to virus infection that limits virus replication and dissemination (O'Brien 1998; Roulston et al. 1999; Barber 2001; Clarke and Clem 2003; Imajoh et al. 2004). To counter this response, many viruses have acquired genes during evolution that encode anti-apoptotic proteins to inhibit apoptosis. Insect baculoviruses, for example, encode P35 and inhibitor of apoptosis proteins (IAPs) that inhibit caspases (Clem et al. 1991; Crook et al. 1993; Manji et al. 1997; Clem 2001). Ultimately, however, viruses benefit from apoptosis in that eventual cell death and fragmentation aids virus spread. Thus, for many viruses the inhibition of apoptosis subsides as viral replication nears completion (O'Brien 1998; Roulston et al. 1999; Imajoh et al. 2004).

Because apoptosis can be triggered by virus infection, and no viruses were known to encode caspases, it seemed possible that the cytopathology characteristic of ascovirus infection occurred as an elaborate virus-coded response to programmed cell death initiated by the cell. Studies described below demonstrate apoptosis does occur in caterpillars infected with ascovirus. However, initial studies aimed at searching the genome of the ascovirus type species, the Spodoptera frugiperda ascovirus (SfAV), for genes involved in cell differentiation and viral vesicle formation identified an executioner caspase gene, indicating it may play a direct role in SfAV-induced apoptosis. Here we report the nucleotide and deduced amino acid sequence of this caspase, and show that it has caspase activity, triggers apoptosis in insect cells in vitro, and is associated in vivo with typical early stage apoptotic events including nuclear membrane fragmentation and DNA cleavage. Inhibiting SfAV caspase activity using a caspase inhibitor or RNAi markedly altered 
and reduced cellular cytopathology and subsequent formation of viral vesicles characteristic of ascovirus development and dissemination.

\section{Results and Discussion}

\section{SfAV induces apoptosis in vivo and in vitro}

SfAV infects the fat body of larvae of the lepidopteran genus Spodoptera, and by $4 \mathrm{~d}$ post-infection, blood of these larvae contains millions of viral vesicles per milliliter (Fig. 1A-C). When we infected third instars of Spodoptera exigua with as few as 10 viral vesicles, apoptosis was evident by $48 \mathrm{~h}$ after infection and marked by 72 h. Nucleosomal fragments were observed in DNA prepared from fat tissue isolated from SfAV-infected larvae but not from tissue isolated from uninfected control larvae (Fig. 1D). Sections from SfAV-infected fat tissue were positive by the transferase-mediated dUTP nickend-labeling (TUNEL) staining method (Piqueras et al. 1996), indicating chromosomal fragmentation, whereas fat body of mock-infected larvae was TUNEL-negative and exhibited no fragmentation (Fig. 1E). Similarly, studies in vitro with SF21 cells infected with SfAV exhibited

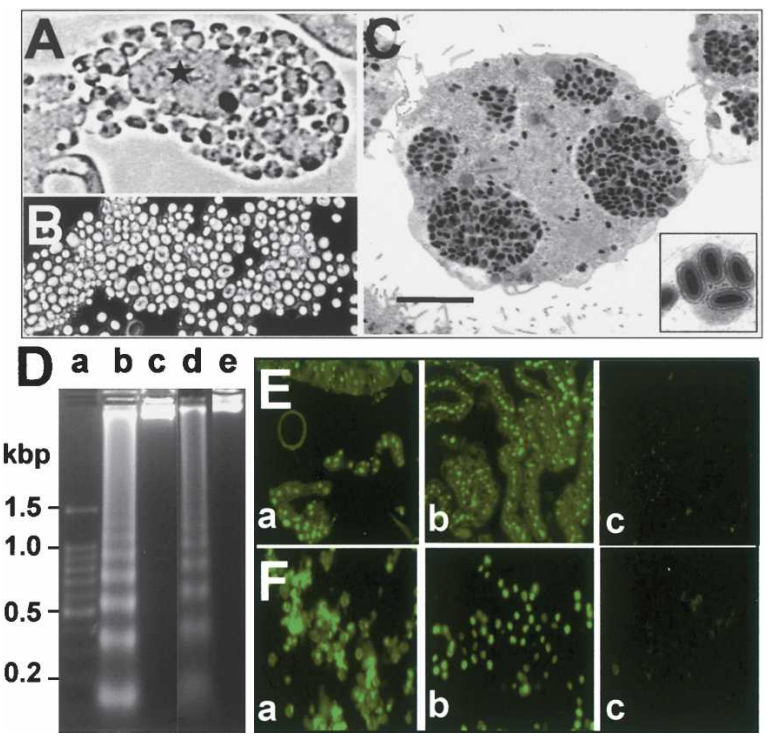

Figure 1. Cytopathology caused by the SfAV in vivo and in vitro. (A) Infected fat body cell in a fourth instar cleaving into numerous viral vesicles (virion-containing vesicles) at $72 \mathrm{~h}$ post-infection. As apoptosis progresses, cleavage and vesicle formation typically proceed from the plasma membrane inward. The central area (star) has not yet formed vesicles. $(B)$ Typical density of viral vesicles in blood at $120 \mathrm{~h}$ post-infection. (C) Electron micrograph of a viral vesicle showing clusters of virions. (Inset) Virions at higher magnification. $(D)$ DNA fragmentation characteristic of SfAV-induced apoptosis in vitro and in vivo: standard DNA ladder (lane a), DNA from SfAVinfected SF21 cells at $12 \mathrm{~h}$ post-infection (lane $b$ ), DNA from uninfected SF21 cells (lane $c$ ), and DNA from SfAV-infected (lane $d$ ) and uninfected (lane e) S. exigua larval fat body. (E) Extensive apoptosis in SfAV-infected fat body tissue of a $S$. exigua fourth instar $72 \mathrm{~h}$ after infection. Tissues were fixed, and fragmented DNA was labeled by terminal deoxynucleotidyl transferase-mediated dUTP nick-end-labeling (TUNEL) to demonstrate apoptosis: infected fat body tissue (panel a), uninfected control treated with DNase I to artificially induce chromosomal fragmentation (panel $b$ ), and uninfected control (panel $c$ ). $(F)$ TUNEL assays of SF21 cells: SfAV-infected cells (panel $a$ ), cells treated with DNase I (panel $b$ ), and mock-infected untreated cells (panel c). Bar, 1 m.
DNA fragmentation characteristic of apoptosis by $24 \mathrm{~h}$ post-infection, but no DNA ladder was observed in mockinfected cells (Fig. 1D). Moreover, $>50 \%$ of the cells were TUNEL-positive by $12 \mathrm{~h}$ post-infection (Fig. $1 \mathrm{~F}$ ).

\section{SfAV encodes a caspase similar to human executioner caspase-3 (apopain)}

In scanning the SfAV genome for genes possibly involved in apoptosis and formation of virion-containing vesicles, we identified and cloned a gene coding for a procaspase of 288 amino acids with a deduced molecular mass of 32.6 $\mathrm{kDa}$ (Fig. 2). Analysis of this caspase (Fig. 2) showed that the two highly conserved and characteristic caspase-1 domains of "p20" and "p10" (Cohen 1997; Lamkanfi et al. 2002) were present along with the binding and catalytic residues typical of the caspase superfamily, and a potential IAP-binding motif similar to that found in human caspase-9 (Liston et al. 2003). However, the SfAV caspase lacked the $\mathrm{N}$-terminal death effector domain (DED) and caspase recruitment domain (CARD) typical of several caspase subfamilies (Bouchier-Hayes and Martin 2002; Lamkanfi et al. 2002). Furthermore, a conserved cysteine residue corresponding to, respectively, C264 and C290 in caspase-3 and caspase-7, but not in initiator caspases, was also present in the SfAV caspase. This cysteine residue in caspase- 3 and caspase- 7 is part of an allosteric site that is functionally coupled to the active site in these enzymes and has been shown to form disulfide bonds with 2-(2,4-dichlorophenoxy)-N-(2-mercapto-ethyl)-acetamide (DICA) and 5-fluoro- $1 H$-indole-2carboxylic acid (2-mercapto-ethly)-amide (FICA) (Hardy et al. 2004). The binding of DICA and FICA to the allosteric site prevents binding of substrate to the active site thereby inactivating these enzymes (Hardy et al. 2004).

Using RT-PCR, we found that the transcript for this gene was present in SF21 cells infected with SfAV by $9 \mathrm{~h}$ post-infection. A PCR product of $1 \mathrm{~kb}$, consistent with the predicted size of the mRNA, was obtained from infected larvae and cells, but not from mock-infected cells (Fig. 3A). To determine whether the activity of this caspase was similar to executioner caspases, a recombinant 6xhis-tagged SfAV caspase (rCasp) was synthesized in Escherichia coli and assayed for its ability to cleave the peptide substrate benzyloxycarbonyl-DEVD-aminoluciferin. Autocleavage and activation of the rCasp was not observed in crude E. coli lysates (Fig. 3B, lane a). However, as with other caspases synthesized in bacteria, during purification the rCasp was cleaved into fragments of lower mass, the lowest, which contained the C-terminal histidine tag, with apparent mass of $17 \mathrm{kDa}$ (Fig. 3B, lane b). Although the cleavage site(s) was not determined, our result suggests that cleavage occurs after the aspartate residues found between positions 149 and 162 (Fig. 2). In this regard, it is interesting to note that cleavage between positions 153 and 154 (QEED/A) would generate a "p10" fragment beginning with AHPT. This tetrad is similar to the IAP-binding motif in mammalian Smac and DIABLO $[\mathrm{AVP}(\mathrm{I} / \mathrm{S})]$, and tetrads in insect Reaper, Hid, and Grim $[\mathrm{A} / \mathrm{V} / \mathrm{I})(\mathrm{P} / \mathrm{A})(\mathrm{F} / \mathrm{Y})]$, proteins that negatively regulate IAP function, and possibly ATPF in the small subunit of caspase-9 (Liston et al. 2003). Whether the AHPT in SfAV caspase inhibits insect-encoded IAPs is unknown, but such a mechanism fits well with the rapid progression of apoptosis in SfAV infected cells and larvae. 
Bideshi et al.

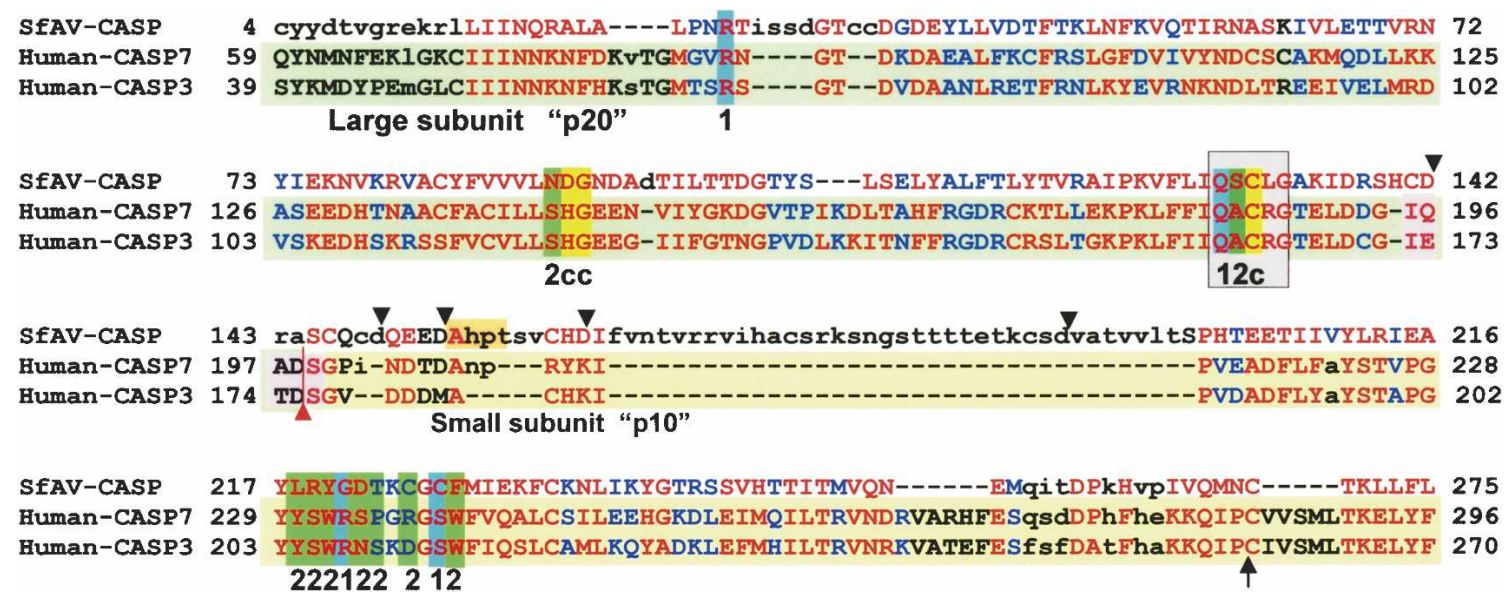

Figure 2. Structural similarity of SfAV caspase to human executioner caspase-3 and caspase-7. Aligned residues are shown in uppercase letters. Moderately similar amino acids are shown in blue, and highly similar or identical residues in red. The recognition residues containing the cleavage site (red arrow) between the large ("p20", highlighted pale green) and small ("p10", highlighted pale yellow) domains in caspase-3 and caspase-7 are boxed in pink. The QACXG catalytic domain conserved in all members of the caspase superfamily is boxed in gray. Amino acid residues essential for catalytic activity (c, bright yellow), form a substrate P1-binding pocket (1, blue) and are adjacent to the substrate P2-P4 amino acids (2, green). The arrowheads indicate potential proteolytic activation sites in SfAV caspase. Cleavage of SfAV caspase at QEED/A would potentially generate a "p10" peptide with the extreme N terminus beginning with AHPT (highlighted light brown), a tetrad that is highly similar to a motif known in IAP-binding proteins. The conserved cysteine residue in the inhibitory allosteric site is also shown (black arrow).

In caspase assays, activated SfAV rCasp cleaved benzyloxycarbonyl-DEVD-aminoluciferin (Fig. 3C). Moreover, SfAV caspase activity was reduced markedly in the presence of the executioner caspase inhibitor, z-DEVD-fmk (Fig. 3C).

The structural motifs along with our sequence analysis and biochemical data suggested that the SfAV caspase is likely an executioner caspase. Thus, we aligned the sequence with other closely related sequences. This analysis, based on the combined p20 and p10 sequences, showed that the SfAV clustered with executioner caspase-3, caspase-6, and caspase-7 (see Supplemental Material), which also lack DED and CARD domains (Lamkanfi et al. 2002).

SfAV caspase induces apoptosis in cultured insect cells and is associated with cellular differentiation in SfAV-infected cells

To determine whether SfAV caspase was capable of inducing apoptosis in vitro, the gene was transfected into cultured cells (TN-5) of Trichoplusia ni and expressed under the control of the cytomegalovirus immediate early promoter/enhancer, a promoter active in TN-5 cells (Fig. 4A). By 30 h post-transfection, cells that synthesized SfAV caspase exhibited extensive blebbing characteristic of apoptosis, whereas mock-transfected cells appeared normal (Fig. 4B). However, unlike SfAV viral vesicles, the resulting apoptotic bodies were smaller and degraded within $48 \mathrm{~h}$ in transfected cell cultures. In addition to blebbing, cells in which the SfAV caspase gene was expressed were TUNEL-positive, whereas no TUNEL-positive cells were detected in mock-transfected cells (Fig. 4C), providing additional evidence that this caspase alone was capable of inducing apoptosis.

To further evaluate whether the SfAV caspase was associated with the formation of virion-containing vesicles characteristic of ascovirus development, we blocked caspase activity with the synthetic peptide benzyloxycarbonyl-DEVD-fluoromethyl ketone (z-DEVD-fmk), a potent inhibitor of executioner caspase activity (Lam- kanfi et al. 2002). In addition, we specifically blocked synthesis of the SfAV caspase using RNAi. Treating SF21 cells prior to infection with $z$-DEVD-fmk resulted in a reduction in cytopathology characteristic of ascovirus

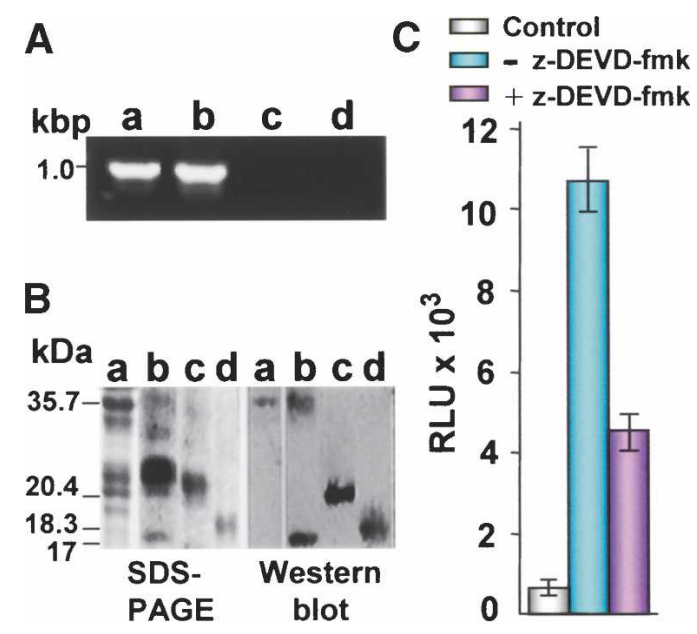

Figure 3. Expression and activity of SfAV caspase. (A) Expression of SfAV caspase gene detected by RT-PCR in SF21 cells $9 \mathrm{~h}$ postinfection with SfAV: PCR control using SfAV viral DNA (lane $a$ ), RT-PCR product obtained using cDNA prepared from SfAV-infected cells (lane $b$ ), RNA control from mock-infected cells (lane $c$ ), and PCR using RNA from SfAV-infected Sf21 cells demonstrating absence of SfAV DNA contamination (lane $d)$. (B) SDS-PAGE and Western blot detection of purified 6xhis-Caspase (rCasp) using an anti-His (C-terminal) antibody: crude preparation showing uncleaved rCasp (lane $a$ ), purified preparation of rCasp demonstrating autocleavage generating smaller fragments including a $17 \mathrm{kDa}$ peptide with the C-terminal histidine tag (lane $b$ ), and recombinant putative $\mathrm{N}$ - and $\mathrm{C}$-terminal SfAV caspase peptide markers with terminal 6xhis tags n-Casp (lane $c$ ) and c-Casp (lane $d$ ). $(C)$ Proluminescent caspase assay using caspase-3/7 substrate z-DEVD-aminoluciferin and rCasp with and without the z-DEVD-fmk inhibitor; the control contained the c-Casp peptide. Luminescence was quantified $3 \mathrm{~h}$ after incubation at room temperature. 
A

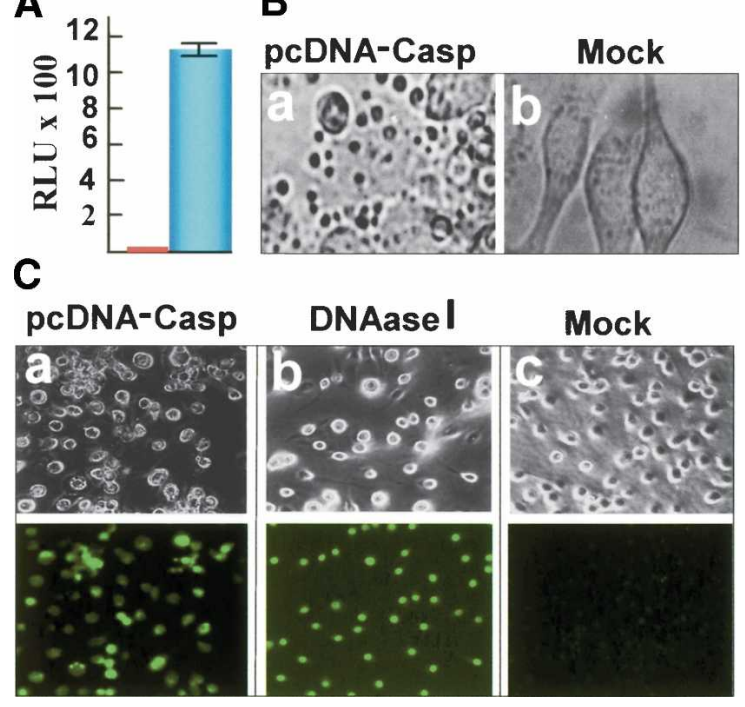

Figure 4. Induction of apoptosis by SfAV caspase gene expressed in vitro in Tn5 cells. $(A)$ Luciferase assay showing the cytomegalovirus immediate early promoter/enhancer is functional in Tn5 (T. ni); mock pcDNA control (red bar) and plasmid pRLCMV with luciferase gene (blue bar). (B) Tn5 cells transfected with $2 \mu \mathrm{g}$ pcDNA-SfAV caspase showing numerous dense spherical apoptotic bodies (panel a) or with $2 \mu \mathrm{g}$ of control plasmid DNA (panel $b)$. (C) Demonstration of apoptosis using TUNEL assay: DNA fragmentation detected with TUNEL in cells transfected with pcDNA-SfAV-casp (panel $a$ ), mocktransfected cells treated with DNase I to artificially induce chromosomal fragmentation (panel $b$ ), and mock-transfected and untreated cells (panel $c$ ).

infection, and especially in the formation of viral vesicles (Fig. 5A). Many cells underwent apoptosis and formed finger-like projections, but typically they failed to cleave into viral vesicles.

In the RNAi experiments, SfAV caspase-specific double-stranded RNA (dsRNA) markedly inhibited formation of viral vesicles by SfAV-infected SF21 cells (Fig. $5 \mathrm{~B})$, but not by infected cells exposed to p35-deficient Autographa californica nucleopolyhedrovirus (vAnhAc) (Clem et al. 1991). By 30 h SfAV caspase RNAi reduced vesicle formation characteristic of this virus from an average of $67 \%$ to $25 \%$ (Fig. 5C). Most cells failed to form viral vesicles, and initiation of vesicle formation by those that did was delayed by at least $24 \mathrm{~h}$, occurring at 3-5 d post-infection compared with the 2-3 d observed for cells infected with SfAV.

\section{Role of SfAV caspase in viral pathobiology}

Our data provide strong evidence that the SfAV caspase plays a direct role in a novel type of apoptosis that yields viral vesicles that enhance virus dissemination and transmission. It is counterintuitive that a virus would encode a caspase, as typically apoptosis is generally regarded as an effective mechanism for limiting virogenesis and viral dissemination to healthy host cells and tissues (Clem et al. 1991; Crook et al. 1993; Manji et al. 1997; Clem 2001; Liston et al. 2003; Salvesen and Abrams 2004). Nevertheless, it is known that apoptosis facilitates virus dissemination in cells in which virus replication has proceeded to an advanced stage. Moreover, Wurzer et al. (2003) have shown recently that ac- tivation of caspase- 3 is crucial for efficient propagation of influenza virus. In the case of SfAV, its unique biology suggests that coding for a caspase accelerates the spread of virions and viral vesicles to the hemolymph, where they can be acquired for transmission by parasitic wasps during oviposition. In most cells infected with DNA viruses in vitro, the onset of apoptosis by cellular caspases does not occur until $\geq 24 \mathrm{~h}$ after infection and may not reach a high level for several days (Roulston et al. 1999; Clarke and Clem 2003; Imajoh et al. 2004). In contrast, we detected SfAV caspase transcripts at $9 \mathrm{~h}$ post-infection in SF21 cells (Fig. 3A). The structure of the SfAV caspase, which lacks DED and CARD domains (Bouchier-Hayes and Martin 2002; Lamkanfi et al. 2002) and contains a potential IAP-binding motif (Liston et al. 2003 ) in its "p10" fragment (Fig. 2), also suggests a structure that accelerates apoptosis, with the latter domain likely serving to block inhibition of normal cell death. In essence, it appears that SfAV, and likely other ascoviruses, has turned the defensive response of its host to its advantage by acquiring a caspase gene from a host cell during evolution. While enhancing virus transmission
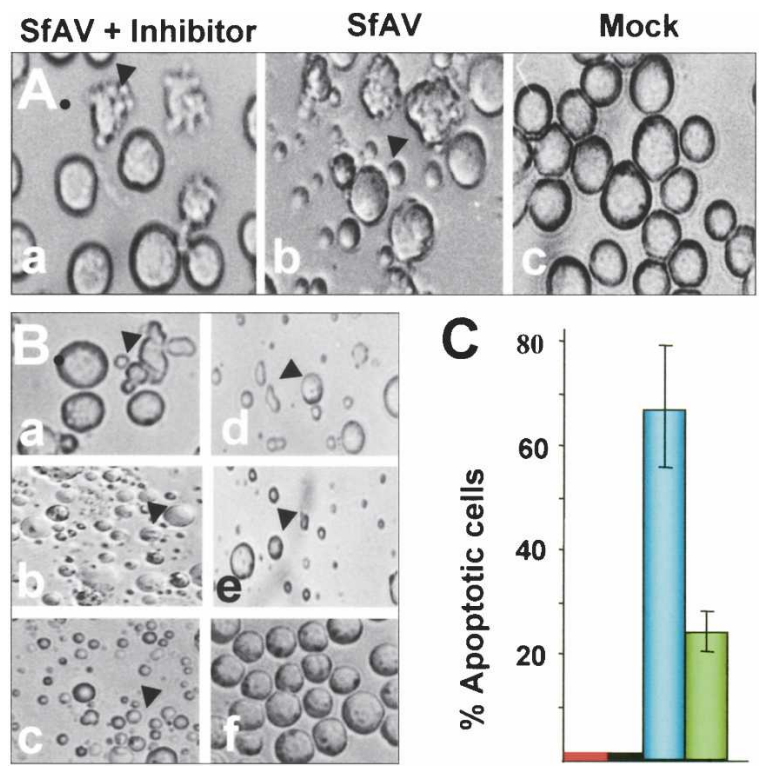

Figure 5. Inhibition of SfAV caspase activity in SF21 cells using a caspase inhibitor (z-DEVD-fmk) or SfAV caspase-specific dsRNA. (A) Effect of a caspase inhibitor on formation of SfAV virion vesicles in SF21 cells: SfAV-infected cell culture with z-DEVD-fmk (panel $a$ ), SfAV infected cell cultures lacking z-DEVD-fmk (panel $b$ ), and mock-infected cells (panel c). Arrowheads indicate virion-containing vesicles. Photographs taken at $96 \mathrm{~h}$ post-infection. (B) Caspasespecific dsRNA inhibition of apoptosis in SF21 cells infected with SfAV. Cells were infected with SfAV followed by transfection with $15 \mu \mathrm{g}$ of SfAV-caspase specific dsRNA (panel $a$ ), infected with SfAV (panel $b$ ), infected with SfAV followed by transfection with unrelated control 28iMAL dsRNA (panel $c$ ), infected with vAnhAc (panel d), vAnhAc and dsRNA (panel $e$ ), and mock-infected with caspasespecific dsRNA (panel $f$ ). (Panels $d$,e) SfAV caspase dsRNA did not inhibit apoptosis in SF21 cells infected with the vAnhAc virus which induced apoptosis. $(C)$ Effect of SfAV caspase-specific dsRNA on the level of apoptosis: mock control with caspase dsRNA (red bar) or 28iMAL dsRNA (black bar), SfAV-infected cells (blue bar), SfAVinfected cells transfected with SfAV caspases-specific dsRNA (green bar). Effect of SfAV caspase-specific dsRNA (\% Apoptotic cells) was assessed as the percentage of cells at $30 \mathrm{~h}$ that initiated apoptosis but failed to form viral vesicles or apoptotic bodies compared with the number of cells infected with SfAV that cleaved into viral vesicles. 
appears to be the primary role of SfAV caspase, it may also be involved with maturation of viral proteins, a role demonstrated for caspase-3 (Best and Bloom 2004).

At present, the evolutionary source of the SfAV caspase gene is not obvious from its sequence, largely because so few caspase sequences are available from known and potential insect hosts. Our previous studies of the molecular evolution of ascoviruses indicate that these viruses evolved from insect iridoviruses (family Iridoviridae) and may be an evolutionary intermediate to the virus-like particles classified as ichnoviruses (family Polydnaviridae), which are vectored by parasitic wasps (Webb et al. 2000; Federici and Bigot 2003; Stasiak et al. 2003). It is therefore likely that the SfAV or one of its progenitors acquired this caspase gene from a lepidopteran or possibly a hymenopteran host, the only two types of insects in which ascoviruses are known to replicate (Federici et al. 2000; Bigot et al. 1997).

The formation of virion-containing vesicles characteristic of all ascoviruses is a complex apoptotic process of highly coordinated cellular reorganization likely involving the interplay of many cellular and viral genes other than the SfAV caspase. SfAV vesicles are basically apoptotic bodies rescued and modified for stability and additional virion production as they circulate in the blood (Hamm et al. 1985; Govindarajan and Federici 1990; Tillman et al. 2004). Whereas we have provided evidence that the SfAV caspase plays a significant role in viral vesicle formation, clearly, as with apoptosis in general, such a complex process involves other viral and cellular genes and functions yet to be identified. Further studies of ascoviruses should provide insights into the evolutionary source of this ascovirus caspase, and identify other genes acquired from host cells during evolution that are involved in the cytopathology that yields the unique virion-containing vesicles characteristic of ascoviruses. Identification of these genes and the functions of the proteins they encode could have practical applications in designing simple, anucleate eukaroytic systems capable of synthesizing large amounts of complex proteins, a characteristic of ascovirus viral vesicles.

\section{Materials and methods}

Viral and lepidopteran species and cell lines

The ascovirus used for these studies was the SfAV, the ascovirus-type species, formally designated as SfAV-1a, but abbreviated throughout the text as SfAV. The in vivo host was the larval stage of the beet armyworm, $S$. exigua. For in vitro studies, two cell lines derived from species of the lepidopteran family Noctuidae were used, SF21 cells derived from $S$. frugiperda and Tn5 cells derived from T. ni (Invitrogen).

\section{Chromosomal DNA fragmentation}

Two methods, agarose gel electrophoresis and the terminal deoxynucleotidyl TUNEL assay (Piqueras et al. 1996), were used to demonstrate chromosome fragmentation in fat body and $S$. frugiperda cells (SF21). These methods are described in the Supplemental Material.

Sequence alignments and phylogenetic analyses

For sequence alignments and phylogenetic analyses, see the Supplemental Material.

Inhibition of SfAV1a-induced apoptosis with synthetic peptide SF21 cells were added to $35-\mathrm{mm}$ culture plates at $\sim 1 \times 10^{5}$ cells/plate with $2 \mathrm{~mL}$ of TC-100/10\% FBS medium containing $266 \mu \mathrm{M} z$-DEVD$\mathrm{fmk}$, a potent synthetic peptide inhibitor of caspase-3, caspase-6, caspase7, caspase-8, and caspase-10 (Santa Cruz Biotechnology). After a 4-h incubation period at $25^{\circ} \mathrm{C}, 2 \mu \mathrm{L}$ of culture medium containing $\sim 2.0 \times 10^{5}$ plaque-forming units (pfu) of SfAV was added to cultures, which were then incubated for $4 \mathrm{~d}$ at $27^{\circ} \mathrm{C}$. For controls, SF21 cells were grown under identical conditions with the inhibitor, or with SfAV without the inhibitor. Experiments were replicated three times.

Caspase and luciferase gene expression, rCasp, and caspase assays For expression in Tn5 cells, the caspase gene was cloned in pcDNA3.1 $1+1$ under control of the cytomegalovirus immediate early promoter (Invitrogen). pRLCMV (Promega) was used in the luciferase assay. The pBAD/ Myc-HisA vector (Invitrogen) was used for expression and synthesis of 6xhis-caspase (rCasp). The Caspase-Glo 3/7 kit (Promega) was used in caspase assays. Detailed methods are described in the Supplemental Material.

RNA interference

dsRNA was synthesized from PCR fragments obtained from pLITcasp and the control pLITMUS 28iMAL using the HiScribe RNAi Transcription Kit and digested with Shortcut RNase III according to manufacturer's protocol (Biolabs). Template DNAs were removed by digestion with RQ1 DNase (Promega). Approximately $3 \times 10^{5}$ SF21 cells were plated in $35-\mathrm{mm}$ culture dishes and overlaid with $1 \mathrm{~mL}$ of culture medium containing SfAV virions or a $p 35$-deficient $A$. californica nucleopolydrovirus (vAnhAc) (Clem et al. 1991) at a multiplicity of infection of $\sim 2 \mathrm{pfu} / \mathrm{cell}$. Virus inoculum was removed after $1 \mathrm{~h}$ and replaced with $1.5 \mathrm{~mL}$ of fresh transfection mix containing $15 \mu \mathrm{g}$ of SfAV caspase-specific dsRNA previously resuspended in $94 \mu \mathrm{L}$ of $1 \times$ Grace's insect tissue culture medium (GIBCO-BRL) and FuGENE 6 transfection reagent (Roche Molecular Diagnostic) according to manufacturer's protocol. Cultures were incubated at $27^{\circ} \mathrm{C}$ for $30 \mathrm{~h}$. Additional controls included virus-infected and uninfected SF21 cells transfected with and without LITMUS 28iMAL and caspase dsRNAs. Experiments were performed in triplicate. Three widely separated areas in each culture dish were selected at random, and 100 cells were counted in each area and scored for apoptosis. Effect of SfAV caspase-specific dsRNA was assessed as the percentage of cells at $30 \mathrm{~h}$ that initiated apoptosis but failed to form viral vesicles or apoptotic bodies compared with the number of cells infected with SfAV that cleaved into viral vesicles.

\section{Acknowledgments}

We thank Sonja M. Best (NIH Rocky Mountain Laboratory, Hamilton, Montana), S. Nelson Thompson, and Jun Ling (University of California, Riverside) for constructively critical reviews and discussions of our results and original manuscript, and Jeffrey J. Johnson for technical assistance. This research was supported in part by grants from the U.S. National Science Foundation (INT-9726818) to B.A.F. and grants from NATO and the French CNRS to Y.B.

\section{References}

Barber, G.N. 2001. Host defense, viruses and apoptosis. Cell Death Differ. 8: 113-126.

Best, S.M. and Bloom, M.E. 2004. Caspase activation during virus infection: More than just a kiss of death? Virology 320: 191-194.

Bigot, Y., Rabouille, A., Sizaret, P.-Y., Hamelin, M.-H., and Periquet, G. 1997. Biological and molecular features of the relationships between Diadromus pulchellus ascovirus, a parasitoid hymenopteran wasp (Diadronmus pulchellus) and its lepidopteran host, Acrolepiopsis assectella. J. Gen. Virol. 78: 1149-1147.

Bouchier-Hayes, L. and Martin, S.J. 2002. CARD games in apoptosis and immunity. EMBO T. 3: 616-621.

Clarke, T.E. and Clem, R.J. 2003. In vivo induction of apoptosis correlating with reduced infectivity during baculovirus infection. J. Virol. 77: 2227.

Clem, R.J. 2001. Baculovirus and apoptosis: The good the bad, and the ugly. Cell Death Differ. 8: 137-143.

Clem, R.J., Fechheimer, M., and Miller, L.K. 1991. Prevention of apoptosis by a baculovirus gene during infection of insect cells. Science 254: 1388-1390.

Cohen, G.M. 1997. Caspases: The executioner of apoptosis. Biochem. J. 326: 1-16.

Crook, N.E., Clem, R.J., and Miller, L.K. 1993. An apoptosis-inhibiting 
baculovirus gene with a zinc finger-like motif. J. Virol. 67: 21682174.

Federici, B.A. 1983. Enveloped double stranded DNA insect virus with novel structure and cytopathology. Proc. Natl. Acad. Sci. 80: 76647668.

Federici, B.A. and Bigot, Y. 2003. Origin and evolution of polydnaviruses by symbiogenesis of insect DNA viruses in endoparasitic wasps. $J$. Insect Phys. 49: 419-432.

Federici, B.A. and Govindarajan, R. 1990. Comparative histology of three ascovirus isolates in larval noctuids. J. Invertbr. Pathol. 56: 300-311.

Federici, B.A. Bigot, Y., Granados, R.R., Hamm, J.J., Miller, L.K., and Vlak, J.M. 2000. Family Ascoviridae. In Taxonomy of viruses: VII report of the International Committee on Virus Taxonomy (eds. M.H.V. van Regenmortel, et al.), pp. 261-265. Academic Press, London.

Govindarajan, R. and Federici, B.A. 1990. Ascovirus infectivity and the effects of infection on the growth and development of noctuid larvae. J. Invertebrate Pathol. 56: 291-299.

Hamm, J.J., Nordlung, D.A., and Marti, O.G. 1985. Effects of nonoccluded virus of Spodoptera frugiperda (Lepidoptera: Noctuidae) on development of parasitoid, Cotesia marginiventris (Hymenoptera: Braconidae). Environ. Entomol. 14: 258-261.

Hardy, J.A., Lam J., Nguyen, J.T., O'Brien, T., and Wells, J.A. 2004. Discovery of an allosteric site in the caspases. Proc. Natl. Acad. Sci., 101: 12461-12466.

Imajoh, M., Sugiura, H., and Oshima, S. 2004. Morphological changes contribute to apoptotic cell death and are affected by caspase- 3 and caspase-6 inhibitors during red sea bream iridovirus permissive replication. Virology 322: 220-230.

Lamkanfi, M., Declercq, W., Kalai, M., Saelens, X., and Vandenabeele, P. 2002. Alice in caspase land: A phylogenetic analysis of caspases from worm to man. Cell Death Differ. 9: 358-361.

Liston, P., Fong, W.G., and Korneluk, R.G. 2003. The inhibitors of apoptosis: There is more to life than Bcl2. Oncogene 22: 8568-8580.

Manji, G.A., Hozak, R.R., LaCount, D.J., and Friesen, P.D. 1997. Baculovirus inhibitor of apoptosis functions at or upstream of the apoptotic suppressor P35 to prevent programmed cell death. J. Virol. 71: 4509-4516.

O'Brien, V. 1998. Viruses and apoptosis. J. Gen. Virol. 79: 1833-1845.

Piqueras, B., Autran, B., Debre, P., and Gorochov, G. 1996. Detection of apoptosis at the single-cell level by direct incorporation of fluorescein-dUTP in DNA strand breaks. BioTechniques 20: 634-640.

Roulston, A., Marcellus, R.C., and Branton, P.E. 1999.Viruses and apoptosis. Ann. Rev. Microbiol. 53: 577-628.

Salvesen, G.S. and Abrams, J.M. 2004. Caspase activation: Stepping on the gas or releasing the brakes? Lessons from human and flies. Oncogene 23: 2774-2784.

Stasiak, K., Renault, S., Demattei, M.V., Bigot, Y., and Federici, B.A. 2003. Evidence for the evolution of ascovirus from iridoviruses. J. Gen. Virol. 84: 2999-3009.

Tillman, P.G., Styer, E.L., and Hamm, J.J. 2004. Transmission of an ascovirus from Heliothis virescens (Lepidoptera, Noctuidae) and effects of the pathogen on survival of a parasitoid, Cardiochiles nigriceps (Hymenoptera, Braconidae). Environ. Entomol. 33: 633-643.

Webb, B.A., Beckage, N.E., Hayakawa, Y., Krell, J.P., Lanzrein, B., Stoltz, D.B., Strand, M.R., and Summers, M.D. 2000. Family Polydnaviridae In Taxonomy of viruses: VII report of the International Committee on Virus Taxonomy (eds. M.H.V. van Regenmortel, et al.), pp. 253260. Academic Press, London.

Wurzer, W.J., Planz, O., Ehrhardt, A., Giner, M., Silberzahn, T., Pleschka, A., and Ludwig, S. 2003. Caspase 3 activation is essential for efficient influenza virus propagation. EMBO J. 22: 2717-2728. 


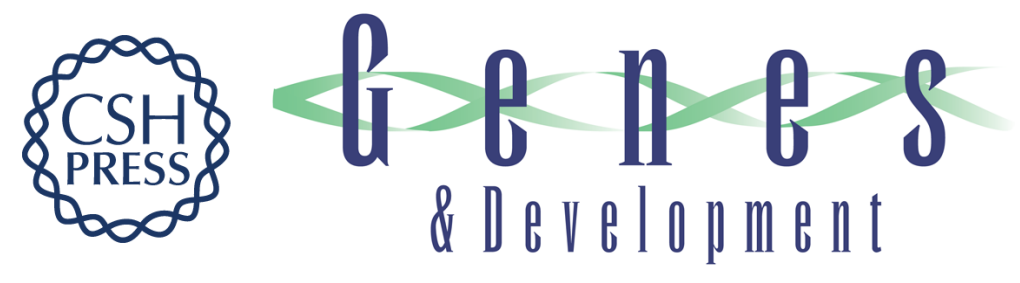

\section{A viral caspase contributes to modified apoptosis for virus transmission}

Dennis K. Bideshi, Yeping Tan, Yves Bigot, et al.

Genes Dev. 2005, 19:

Access the most recent version at doi:10.1101/gad.1300205

\section{Supplemental http://genesdev.cshlp.org/content/suppl/2005/06/03/gad.1300205.DC1 Material}

References This article cites 25 articles, 7 of which can be accessed free at: http://genesdev.cshlp.org/content/19/12/1416.full.html\#ref-list-1

\section{License}

Email Alerting

Receive free email alerts when new articles cite this article - sign up in the box at the top Service right corner of the article or click here.

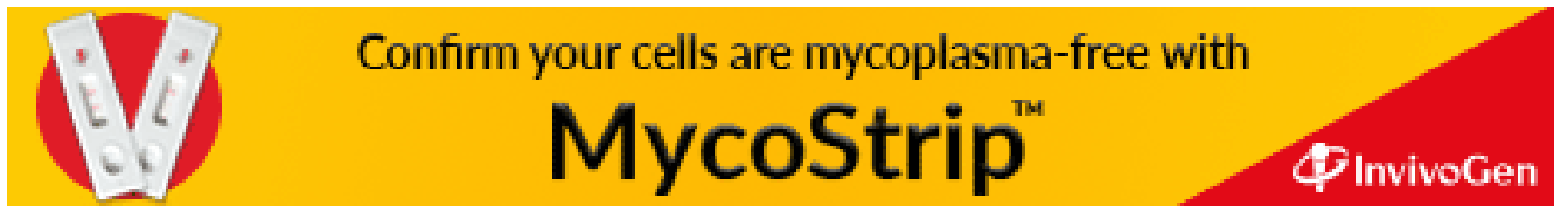

